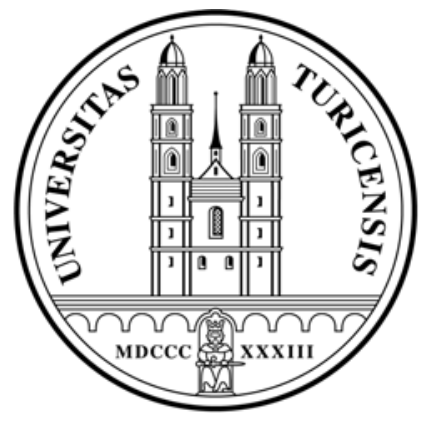

Institute for Empirical Research in Economics

University of Zurich

Working Paper Series

ISSN 1424-0459

Working Paper No. 376

Securitization of Mortgage Debt, Asset Prices and International Risk Sharing

Mathias Hoffmann and Thomas Nitschka

December 2008 


\title{
Securitization of Mortgage Debt, Asset Prices and International Risk Sharing ${ }^{1}$
}

\author{
Mathias Hoffmann ${ }^{2}$ \\ Thomas Nitschka \\ University of Zurich \& CESifo \\ University of Zurich
}

This version: December 2008.

http://www. iew.uzh.ch/itf

\footnotetext{
${ }^{1}$ An earlier version of this paper was circulated unter the title Home Bias: Asset Prices, Securitization of Mortgage Debt and International Risk Sharing. We have benefited from remarks by seminar participants at the ZEW-Bundesbank Workshop on Housing and Asset Markets, the 3rd Zurich Macroeconomics and Finance Conference and at University of Stirling. In particular, we would like to thank Philipp Harms for his detailed discussion of the paper. We are also grateful to Sascha Becker and Jean Imbs for useful suggestions. Any errors remain entirely our own.

${ }^{2}$ Both authors are at University of Zurich, Institute of Empirical Research in Economics, Chair of International Trade and Finance, Zürichbergstrasse 14, CH8032 Zurich, Switzerland.

E-Mail: mathias.hoffmann@iew.uzh.ch and thomas.nitschka@iew.uzh.ch
} 


\begin{abstract}
We explore the impact of mortgage securitization on the international diversification of macroeconomic risk. By making mortgage-related risks internationally tradeable, securitization contributes considerably to better international consumption risk sharing: we find that countries with the most highly developed markets for securitized mortgage debt have consumption responses to a typical idiosyncratic business cycle shock that are 20-30 percent less volatile than those experienced by countries that do not allow for mortgage securitization. Our results are based on quarterly data from a panel of 16 industrialized countries and cover the sample period 19852008Q1. They are robust to a range of controls for other aspects of financial globalization, international differences in the structure of housing markets and the financial system etc. Against the backdrop of the subprime crisis, these findings inevitably raise the question whether securitization could not just facilitate risk sharing in tranquil times but that it actually fails to provide international insurance in severe crisis periods. Indeed, we find that international risk sharing decreases in global asset price downturns and increases in booms. But we do not find evidence that countries with more developed securitization markets are systematically more exposed to these fluctuations in the extent to which risk can be shared across national boundaries.

KEYWORDS: FINANCIAL GLOBALIZATION, INTERNATIONAL RISK SHARING, HOME BIAS, SECURITIZATION, MORTGAGE MARKETS, ASSET PRICES, INTERNATIONAL BUSINESS CYCLES
\end{abstract}

JEL Classification: F 36, F37, F 41, G15, G21 


\section{Introduction}

The securitization of mortage-related debt has played a major role in the emergence and proliferation of the current financial crisis (see Brunnermeier (2008) for a detailed account). Understandably, this has led to widespread scepticism with respect to the usefulness of such instruments for an efficient allocation of macroeconomic risk. From the current experience it seems obvious that the repackaging of mortgage debt in mortgage backed securities (MBS) can have enormous aggregate $\operatorname{costs},{ }^{1}$ but to date no empirical account of the macroeconomic benefits of these instruments exists.

In this paper we contribute to filling this gap by exploring the impact that the increasing use of mortgage securitization has had on the international diversification of macroeconomic risk. From a theoretical point of view, one may expect that the impact of mortgage securitization could be large. Mortgage markets are internationally far less integrated than say equity or bond markets. Residential real estate is largely domestically financed in most economies, making fluctuations in the value of housing and the quality of mortgage debt a major background risk from the perspective of an individual country. That the idiosyncratic component of such risks is likely to be significant is illustrated in figure (1), which plots the international correlation of stock markets against that of residential housing prices: for all of the 120 country pairs considered here, housing prices have much lower international correlations than stock markets. This implies that fluctuations in the value of residential real estate (or of the debt collateralized on it) are a significant idiosyncratic risk from the perspective of the individual economy.

\footnotetext{
${ }^{1}$ See Keys et al. (2008) and Mian and Sufi (2008) for detailed empirical accounts of how the originate-to-distribute model has led to moral hazard and lax screening in the run-up to the subprime crisis. Demyanik and Van Hemert (2008) argue that even though loan quality in the U.S mortgage market deteriorated long before the crisis, securitizers were to some extent aware of this.
} 
Securitization can help diversify such risks internationally because it makes mortgage-debt internationally tradeable.

Our evidence strongly supports this theoretical conjecture: we find that over the last 20 years, the increasing securitization of mortgage debt has contributed considerably to better international consumption risk sharing. The effect is large: the countries with the most highly developed markets for mortgage backed securities have consumption volatilities in response to a typical idiosyncratic business cycle shock that are 20-30 percent lower than experienced by countries that do not allow for securitization. These results are robust to a range of controls for other aspects of financial globalization, international differences in the structure of housing markets and the financial system etc.

If securitization carries benefits in terms of better international risk sharing, this inevitably raises the question whether the costs inflicted by a major downturn such as the current one could not still outweigh the potential welfare benefits of better international risk sharing by an order of magnitude. Securitization may well facilitate risk sharing in tranquil times, but it might actually make things worse in a crisis. We attempt to provide a quantitative impression of this trade-off by asking to what extent international risk sharing is dependent on the state of global asset markets. Indeed, we find that international risk sharing increases in asset price booms and decreases in recessions. At least based on data from previous asset market downturns, we do not find evidence that the ability to share risk across national boundaries is generally more dependent on global asset market conditions in countries with high levels of securitization than in countries where no secondary markets for mortgage-debt exist. Our (macroeconomic) data set covers the period from 1985 to the first quarter of 2008. Hence, it includes 
the onset of the current turmoil but does not yet cover the further unfolding of events, including the demise of Fannie Mae and Freddie Mac or the aftermath of the bankruptcy of Lehman Brothers. The judgement on the role of securitization for international transmission and risk sharing in the current crisis is necessarily bound to remain out for now and we therefore do not attempt to say anything on it here. We note, however, that recent events are certainly in line with the view that securitization has contributed to turning this crisis into the first globalized real estate bust. The fact that the costs of the crisis are spread internationally - for better or worse - indicates that markets for securitized mortgage credit $d o$ seem to provide international risk sharing.

Our paper stands in the tradition of an empirical literature on international consumption risk sharing, building on Sørensen and Yosha (1998) and Crucini (1999). A number of papers in this branch of the literature have recently come to document a positive impact of financial globalization on international risk sharing (see Imbs (2006), Sørensen et al. (2007), Artis and Hoffmann $(2007,2008))$. Our paper is also closely related to work on deregulation and risk sharing, specifically to Demyanik et al (2007) who have investigated the impact of banking deregulation on interstate risk sharing in the US.

Very few papers have recognized the possibility that the extent of risk sharing might vary over the economic cycle or with asset prices. We explore this possibility here. In this respect we build on Hoffmann and Shcherbakova (2008) and Lustig and van Nieuwerburgh (2005, 2006). Hoffmann and Shcherbakova (2008) show that interstate risk sharing in the U.S. increases in booms and decreases in recessions. This cyclical dependence has, however, been mitigated as a consequence of the liberalization of interstate banking 
markets during the 1980s. Here we adapt the empirical framework of this previous study to explore the role that asset prices play for risk sharing among countries. Another closely related paper is Lustig and van Nieuwerburgh (2006) who explore the role of time variation in collateral availability for interstate risk sharing.

The paper is now structured as follows. In the next section, we present our empirical framework. Section three presents our data set. Section four presents the bulk of our empirical results. Section five summarizes and concludes.

\section{International Risk Sharing and the securitiza- tion of mortgage debt}

We measure consumption risk sharing through panel regressions of the form

$$
\Delta \log \frac{C_{t}^{k}}{C_{t}^{*}}=\beta_{U}\left[\Delta \log \frac{G D P_{t}^{k}}{G D P_{t}^{*}}\right]+\varepsilon_{t}^{k}
$$

where $C_{t}^{k}$ is per capita consumption in country $k$ in period $t, G D P_{t}^{k}$ is the country's output per head and the asterisk denotes the international per capita average of the respective variable. In such a regression, we can think of the estimate of $\beta_{U}$ as measuring the amount of uninsured idiosyncratic output risk.

Regressions such as (1) by now have some tradition in both the microeconometric as well as in the macro literature. Mace (1991), Cochrane (1991) and Townsend (1994) were the first to suggest regressions similar to (1) on household level data as a test of the null of complete markets. In a world with complete markets, growth in marginal utility should be equated 
across regions, so that in all states of nature:

$$
\frac{u^{\prime}\left(C_{t+1}^{k}(s)\right)}{u^{\prime}\left(C_{t}^{k}(s)\right)}=\lambda(s)
$$

where $s$ indexes the state of nature and $\lambda$ is the growth rate in the shadow price of consumption. ${ }^{2}$ A key implication of (2) is that if risk is efficiently allocated, marginal utility growth should be independent of country-specific variables. To the extent that we can associate changes in marginal utility with consumption growth, consumption growth should therefore be independent of a country's business cycle risks - regressions of the form (1) should yield a coefficient of zero. More recently, Asdrubali, Sørensen and Yosha (1996) and Sørensen and Yosha (1998) have argued that the estimate of $\beta_{U}$ may be more generally informative: even if the null of complete financial markets is rejected, $\beta_{U}$ still is a measure of market incompleteness. In panel regressions, $\beta_{U}$ is regularly between 0 and unity, so that $1-\beta_{U}$ can straightforwardly be interpreted as the share of the average country's idiosyncratic business cycle risk that gets laid off in financial markets, whereas $\beta_{U}$ is the portion of non-diversified idiosyncratic risk faced by the average country.

Early estimates of $\beta_{U}$ based on international data typically were in the range between 0.7 and 0.8 . Estimates based on more recent data are typically considerably lower, reflecting the effect of financial globalization on international risk sharing (see Sørensen et al (2007), Artis and Hoffmann (2008)).

In this paper, we wish to explore to what extent $\beta_{U}$ varies across coun-

\footnotetext{
${ }^{2}$ This formulation of the optimal risk sharing condition abstracts from real exchange rate fluctuations (see Backus and Smith (1993)). Here, we follow the bulk of the literature on international consumption risk sharing that has predominantly used risk sharing regressions such as (1) to study the impact of globalization on risk sharing. Hoffmann (2008) reports the conclusions as to how much risk is shared through financial markets remain unaffected by controlling for real exchange rate movements in regressions such as (1).
} 
tries depending on whether and to which degree securitization of mortgage related debt is used. Our basic tool will be panel regressions in which we parametrize the coefficient $\beta_{U}$ as a linear function of securitization and of other country- and time-varying controls, so that

$$
\beta_{U}^{k}(t)=\beta_{0}+\mathbf{z}_{t}^{k \prime} \boldsymbol{\beta}_{z}
$$

where $\mathbf{z}_{t}^{k}$ is a vector containing time-varying and country-specific characteristics. We partition $\mathbf{z}_{t}^{k}$ into aggregate, $\mathbf{x}_{t}^{\prime}$, and (time-invariant) countryspecific characteristics, $\boldsymbol{v}^{k}$. In addition, we also allow for some characteristics to vary by country and time, $\mathbf{y}_{t}^{\prime k}$, so that $\mathbf{z}_{t}^{k \prime}=\left[\mathbf{x}_{t}^{\prime}, \boldsymbol{v}^{\prime k}, \mathbf{y}_{t}^{\prime k}\right]$.

We then specify a panel risk sharing regression of the form

$$
\Delta \widetilde{c}_{t}^{k}=\beta_{u}^{k}(t) \Delta \widetilde{g d p}_{t}^{k}+\alpha+\delta^{k}+\tau_{t}+\varepsilon_{t}^{k}
$$

where $\delta^{k}$ is a country-fixed effect and $\tau_{t}$ a common time effect. Here, and in the remainder of the paper, we use lower-case letters to denote logarithms, so that $\widetilde{\Delta c_{t}^{k}}=\Delta \log \left[C_{t}^{k} / C_{t}^{*}\right]$. Plugging (3) into this regression specification and controlling for first-order partial effects we obtain an estimable relation which is

$$
\Delta \widetilde{c}_{t}^{k}=\beta_{0} \Delta \widetilde{g d p_{t}^{k}}+\mathbf{z}_{t}^{k \prime} \boldsymbol{\beta}_{z} \Delta \widetilde{g d p_{t}^{k}}+\mathbf{y}_{t}^{k \prime} \boldsymbol{\gamma}+\alpha+\delta^{k}+\tau_{t}+\varepsilon_{t}^{k}
$$

Note that in this specification we will not generally need to include all the uninteracted terms $\mathbf{z}_{t}^{k}$. The reason for this is that the time-variation in aggregate variables will be captured through the panel time-specific effects. Equally, as long as the country-specific characteristics are assumed to be time-invariant, these will be fully captured by the country fixed-effects. Hence, the specification above will include the first-order terms only for 
$\mathbf{y}_{t}^{k}$, characteristics (such as our indicator of securitization) that vary across countries and time.

In our baseline specification, the vector $\mathbf{z}_{t}^{k}$ will include a qualitative measure that indicates to what extent mortgage securitization can actually be used in country $k$ in year $t .{ }^{3}$ We abbreviate this indicator with $S E C_{t}^{k}$ so that the baseline regression we estimate is

$$
\Delta \widetilde{c}_{t}^{k}=\beta_{0} \Delta{\widetilde{g d p_{t}}}^{k}+\beta_{1} S E C_{t}^{k} \times \Delta{\widetilde{g d p_{t}}}^{k}+\gamma_{1} S E C_{t}^{k}+\alpha+\delta^{k}+\tau_{t}+\varepsilon_{t}^{k}
$$

We enrich this specification as we go along with a range of controls for financial globalization, other characteristics of the financial system and the housing market etc. In addition, we conduct a number of simulation and sample split exercises. Our result is quite clear cut: $\beta_{1}$ is significantly negative - the securitization of mortgage debt seems to be associated with better international risk sharing. Before presenting these results, we describe our data set.

\section{Data}

\subsection{Country sample, output and consumption data}

Our sample comprises the following countries: Australia, Belgium, Canada , Denmark, Finland, France, Germany, Italy, Japan, the Netherlands, Norway, Spain, Sweden, Switzerland, United Kingdom and the United States.

We obtain quarterly, real consumption p.c. and real GDP p.c. from the IMF's Financial Statistics. Consumption and GDP are deflated with the respective countries' CPI and population figures. International consumption and GDP are calculated by normalizing price indices of all countries to 100

\footnotetext{
${ }^{3}$ In the next section, we describe in detail how we constructed this measure.
} 
in 1998Q4 and by converting GDP of each country into 1998Q4 dollar values as in Sørensen et al. (2007).

Unless otherwise noted, the sample period for all our regression specifications is $1985 \mathrm{Q} 1$ to $2008 \mathrm{Q} 1$.

\subsection{Measuring the Securitization of Mortgage Debt}

In our empirical analysis, we propose a qualitative indicator of securitization that we abbreviate with $S E C_{t}^{k}$. We codify $S E C_{t}^{k}$ based on the information on the use of mortgage backed securities from Tsatsaronis and Zhu (2004) and date the start of mortgage securitization in a country based on information from the OECD (Girouard and Blöndal, 2001), the ECB (ECB, 2003) and national sources. Before the de iure introduction of securitization in country $k$, we assign a value of zero to $S E C_{t}^{k}$. From the date when securitization was introduced onwards, $S E C_{t}^{k}$ is assigned a positive value between zero and unity, depending on the degree to which the secondary market mortgage debt is liberalized:

$$
S E C_{t}^{k}=\left\{\begin{array}{cr}
1 & \text { liberalized market for mortgage backed securities } \\
0.3 & \text { intermediate forms of securitization } \\
0 & \text { no securitization allowed. }
\end{array}\right.
$$

Specifically, we set $S E C_{t}^{k}$ to unity for all countries that, in a given period $t$, have an essentially fully liberalized secondary market for mortgage backed securities (MBS). For the US, which has probably the most liquid market for MBS and where these instruments have been in use since after the great depression, $S E C$ is unity for the entire sample period (which for most specifications will start from 1985). Our indicator switches from zero 
to unity for those countries that during our sample period undertook major liberalizations by allowing a far-reaching use of securitized mortgage debt: Australia (1995), Canada (1987), the Netherlands (1996), Spain (1992) and the United Kingdom (1987).

There are some countries that do allow for a somewhat more limited degree of securitization, e.g. in the form of "Pfandbriefe" ( a special form of covered bonds) as in Germany, Switzerland or Sweden (see Tsatsaronis and Zhu (2004)). For this second group of countries we assign a value of $S E C_{t}^{k}=$ 0.3. ${ }^{4}$ Germany, Sweden and Switzerland have a long tradition of using these assets that by far precedes our sample period, so that $S E C$ is constant for these countries. ${ }^{5}$ Countries that introduced similar intermediate forms of securitization during our sample period and for which $S E C_{t}^{k}$ switches from zero to 0.3 were Finland (1989) and France (1991). Finally, some countries do not so far allow any form of securitization of mortgage debt so that $S E C_{t}^{k}=0$ for the entire sample period. This third group includes Denmark, Italy, Japan, Belgium and Norway.

Figure (2) provides an optical impression of how the use of securitization in mortgage markets spread across countries and over time: at each point in time we report the cross-sectional average of $S E C_{t}^{k}$. As is apparent from the graph, there is considerable variation in the degree to and the exact time at which countries would allow securitization of mortgage debt. There is, however, virtually no change in countries' relative positions in terms of securitization before the late 1980s. Our analysis therefore focuses mainly on the period since 1985 .

\footnotetext{
${ }^{4}$ We experimented with various values from 0.1 . to 0.5 to qualitatively account for this mezzanine form of mortgage securitization. None of our results depends on the particular choice of value.

${ }^{5}$ E.g. "Pfandbriefe" as a means of mortgage securitization first emerged in late 19th century Prussia
} 
There are two reasons why we use a qualitative measure of securitization instead of a volume-based measure: the first is that data on the actual extent to which mortgage debt is securitized is not available for many countries and over long time spans. This makes the use of a volume-based measure all but impossible for our purposes.

The second, potentially even more important reason is that the qualitative measure not only focuses on the amount of outstanding securitized debt but also on the ease at which this debt can be traded and the extent to which the issuer remains exposed to fluctuations in the value of the collateral. These legal differences should matter for risk sharing because they mean that securities collateralized by mortgage debt may effectively represent different assets when issued in different countries and under different jurisdictions. Clearly, such differences cannot be captured by a sheer comparison of volumes or by looking at the share of securitized debt in total outstanding mortgage debt. ${ }^{6}$

Nonetheless we attempted to collect time series on outstanding securitized mortgage debt and were successful for a subset of countries in our sample, even though the comparability of these data across countries remains an issue. We describe these data and their relation to the qualitative securitization measure in the appendix, where we also present further robustness checks based on the volume-based measures. In spite of our reservations concerning the volume-based measures, the results from this exercise line

\footnotetext{
${ }^{6} \mathrm{~A}$ point in case is the disctinction between covered bonds and mortgage backed securities. Switzerland and Germany are countries with relatively large markets for covered bonds, but the issuers remain exposed in the sense that they have to ensure that the collateral remains of good quality by taking individual bad loans out. This is marked contrast to the MBS that are in use, say, in the United States. Though the more far-reaching form of securitization in the US may raise important issues of moral hazard, it may still be more effective with respect to risk sharing. This line of reasoning is supported by the results of Loutskina and Strahan (2009) who find that securitization has lowered the dependence of credit supply on lender financial conditions. We would expect this to improve the risk sharing possibilities of borrowers.
} 
up with our results from the qualitative measure as we present them in the main body of the paper.

\subsection{Other mortgage market characteristics}

In the course of our analysis, we will check whether our securitization indicator could not just pick up other characteristics of national mortgage markets and of the financial system more generally. Specifically, we look at how mortgage interest rates are set (fixed vs. flexible), the possibility for mortgage equity withdrawal, the maximum loan-to-value ratio and the valuation method used (historical property valuation vs. market value method). For all these mortgage market characteristics we construct dummies, assigning the values provided in table 2 of Tsatsaronis \& Zhu (2004) to the countries in our sample.

\subsection{Indicators of financial globalization and asset prices}

An additional robustness check we will perform is to assess the importance of the increase in cross-holdings of foreign assets for our results. We employ the Lane and Milesi-Ferreti $(2003,2007)$ external wealth of nations (EWN) dataset for this exercise and calculate their measures of financial integration based on gross foreign asset and liability positions: $g f a_{t}^{k}=\frac{\left(F A_{t}^{k}+F L_{t}^{k}\right)}{G D P_{t}^{k}}$ with $F A_{t}^{k}$ gross foreign assets of country $k$ at time $t$ and $F L_{t}^{k}$ gross foreign liabilities of country $k$ at time $t$ as well as a purely equity-based measure: $g e q_{t}^{k}=\frac{P E Q A_{t}^{k}+P E Q L_{t}^{k}+F D I A_{t}^{k}+F D I L_{t}^{k}}{G D P_{t}^{k}}$ with $P E Q A_{t}^{k}\left(P E Q L_{t}^{k}\right)$ the stock of portfolio equity assets (liabilities) and $F D I A_{t}^{k}\left(F D I L_{t}^{k}\right)$ the stock of direct investment assets (liabilities). Since the EWN data is annual, we calculate quarterly estimates by linear interpolation of year to year growth rates. As an alternative to the linear interpolation we also calculate quarterly values 
using our measure of global asset market conditions (see below) as a scaling factor for the interpolated trend in $g f a$ and $g e q$.

As measure of swings of global asset prices, we consider short-run variations of the U.S. consumption-wealth ratio that we approximate using Lettau's and Ludvigson's (2001) cay, the residual of a cointegrating relationship between consumption, asset wealth and labor income for the US. Lettau and Ludvigson show that cay is an excellent indicator of asset price cycles in US data. Nitschka (2007) extends this result by showing that cay explains a large share of the variation in asset prices in a cross-section of industrialised economies. We therefore use cay as an indicator of global asset market conditions. The data is freely available on Martin Lettau's website: http://faculty.haas.berkeley.edu/lettau/data/cay_q_07Q4.txt

\section{Results}

Table I displays the results from our baseline regression (5):

$$
\Delta \widetilde{c}_{t}^{k}=\beta_{0} \Delta{\widetilde{g d p_{t}}}^{k}+\beta_{1} S E C_{t}^{k} \times \Delta{\widetilde{g d p_{t}}}^{k}+\gamma_{1} S E C_{t}^{k}+\alpha+\delta^{k}+\tau_{t}+\varepsilon_{t}^{k}
$$

We report results for the sample period from 1985Q1 to 2008Q1 in panel A of Table I. Robust t-statistics appear below the estimates in parentheses. Taken alone, the estimate of $\beta_{0}$ in panel A would suggest that about $79 \%$ of international consumption risk remains uninsured in the time period from 1985Q1 to 2008Q1. However, the impact of securitization on risk sharing as mirrored in the $\beta_{1}$ coefficient is not negligible. Securitization improves risk sharing. The coefficient $\beta_{1}$ is negative, significant and the effect is large: for the sample period from 1985 to 2008 the estimate of $\beta_{1}$ implies that

the countries with the most liquid markets for securitized mortgage debt 
achieved 35 percentage points more consumption risk sharing than countries in which securitization of mortgage debt is not allowed.

Panel B of Table I shows the corresponding estimates for the time period from 1995Q1 - 2008Q1. In that time period almost all of the countries under study introduced some form of mortgage payments securitization. Our main conclusion does not only remain unaltered but is even more pronounced. Securitization seems to have an even stronger repercussion on international consumption risk sharing.

A sceptic might argue that we put a lot and maybe too much emphasis on the equity price surge in the late 1990s as well as the house price upswing in recent years. Panel $\mathrm{C}$ reports our basline regression estimates for the time period from 1985Q1 to 1996Q4, thus excluding the impact of global asset price movements in the past decade. The estimate of $\beta_{0}$ remains almost unaltered. Not surprisingly, the effect of securitization on international risk sharing is weaker $\left(\beta_{1}=-0.23\right)$ but the estimate remains highly significant.

The results in Table I are suggestive of a beneficial impact of the securitization of mortgage-related risks on international risk sharing. The subsample analysis shows that this effect is most pronounced in recent years consistent with the view that securitization really took off in the 1990s. Figure 3 displays the amount of home mortgages outstanding used to back securities in the U.S. This data is from the Federal Reserve's Flow of Funds Accounts and covers the period from 1985Q1 to 2008Q1. It underscores that securitization gained importance during the 1990s with a clear upward trend and explosive growth starting around $2004 .{ }^{7}$ However, even if we negelect the past decade, securitization of mortgage related risks still has a significant beneficial impact on international risk sharing.

\footnotetext{
${ }^{7}$ While we do not have comparable data for most other countries, for those we do (such as e.g. Australia), similar trends are discernible.
} 
Our findings inevitably raise the question whether mortgage securitization could not be associated with other time-invariant country-characteristics, such as e.g. a more market based financial system, which would itself lead to more international risk sharing. We address this concern by sorting the 16 countries under study into three bins according to their level of securitization as indicated by $S E C_{t}^{k}$ : the lowest quartile (bin 1), the second and third quartile (bin 2) and the highest quartile (bin 3). We repeat this sorting procedure every quarter for the time period from 1985Q1 to 2008Q1 such that we obtain three synthetic panels of representative observations for low, middle and high securitization country samples. Since our measure of securitization takes discrete values, the sorting of countries into bins at a given point in time may not always be unique. To resolve potential ties, in each period, we add small white noise random disturbances to $S E C_{t}^{k}$ and perform the sorting into bins based on this noisy measure. ${ }^{8}$ We then estimate the risk sharing regression

$$
\Delta \widetilde{c}_{t}^{k}=\beta_{U} \Delta{\widetilde{g d p_{t}}}^{k}+\alpha+\delta^{k}+\tau_{t}+\varepsilon_{t}^{k}
$$

for the low securitization and the high securitization bins, separately, i.e. for $k \in I_{t}^{\text {high }}$ and $k \in I_{t}^{\text {low }}$ where $I_{t}^{\text {high }}$ and $I_{t}^{\text {low }}$ denotes the set of countries that have the highest/lowest degree of securitization at time $t$.

We repeat this exercise 100 times (each time disturbing $S E C_{t}^{k}$ with small shocks) to obtain a series of risk sharing coefficients, $\beta_{U}$, for the high and low securitization groups that is immune against a specific and possibly biased sorting of countries into the high and low securitization

\footnotetext{
${ }^{8}$ We choose the variance of the noise term sufficently low so that the randomization does not affect the ordering across categories, i.e. a country with $S E C_{t}^{k}=1$ will always be considered more liberalized than a country with $S E C_{t}^{k}=0.3$.
} 
bins. Table II presents the average of these risk sharing coefficient estimates. About $77 \%$ of consumption growth risks of the low securitization group remain uninsured while the high securitization group countries leave on average $60 \%$ of consumption growth not shared. Countries that have the opportunity to share their mortgage risks internationally via financial markets reduce the exposure of consumption to idiosyncratic output shocks by $22 \%((0.77-0.60) / 0.77)$ compared to countries that do not allow for mortgage backed securities. Note that in our procedure observations on idiosyncratic consumption and GDP growth change panel group affiliation as countries change their relative degree of securitization. Therefore, these results strongly indicate that the effect of securitization on risk sharing that we pick up here is systematic and not likely to be incidentally related to other, unobserved (or uncontrolled) country-characteristics.

Taken together our main findings suggest that the securitization of mortgage related risks considerably improves international risk sharing. In the remainder of this paper we assess the robustness of this conclusion further.

\subsection{Securitization and international financial integration}

Securitization of mortgage related debt seems to improve international risk sharing, which suggests that it is an important aspect of financial globalization. However, this could just be another facet of the secular growth in international gross asset holdings that we have seen since the early/mid 1990s (see Lane and Milesi-Ferretti (2003, 2007)). Sørensen et al. (2007) and Artis and Hoffmann (2008) document that the increase in cross-border asset holdings is echoed in improved international consumption risk sharing. Since the increase in gross foreign asset holdings worldwide coincides with the period at which securitization has been introduced in various countries 
in our sample, our securitization indicator could just pick up this trend in financial globalization. Not so: we parameterize risk sharing as a function of a financial globalization trend

$$
\beta_{U}^{k}(t)=\beta_{0}+\beta_{1} S E C_{t}^{k}+\beta_{2} g f a_{t}+\beta_{3} g f a_{t} \times S E C_{t}^{k}+\beta_{4} t
$$

where $t$ denotes a time trend and $g f a_{t}=\sum_{k=1}^{16} \frac{\left(F A_{t}^{k}+F L_{t}^{k}\right)}{G D P_{t}^{k}}$ summarizes the average gross foreign asset positions of the countries under study relative to GDP with $F A_{k t}\left(F L_{k t}\right)$ denoting gross foreign assets (liabilities) of country $k$ at time $t$. Lane and Milesi-Ferretti $(2001,2003,2007)$ propose $g f a_{t}$ as a measure of the trend in financial integration. As data of foreign asset positions is only available until the end of 2004 we have to restrict our sample period to 1985Q1 - 2004Q4. Quarterly estimates of gross foreign assets are obtained through linear interpolation. Table III summarizes the results. None of our results changes if we use a purely equity-based measure of financial integration, $g e q_{t}=\sum_{i=1}^{16} \frac{\left(P E Q A_{t}^{k}+P E Q L_{t}^{k}+F D I A_{t}^{k}+F D I L_{t}^{k}\right)}{G D P_{t}^{k}}$ (see Table A.I in the appendix) and/or calculate quarterly estimates that are not based on linear interpolation but rely on movements in global asset prices. In addition, our main result remains unaltered if we consider $g f a_{t}^{k}$ or $g e q_{t}^{k}$ as measures of financial integration, i.e. we take into account the different degree of financial integration across countries. Table A.II and A.III in the appendix present the corresponding regression estimates.

The first line of Table III gives our basic risk sharing regression for that time period, now also taking account of a linear time trend interacted with GDP growth. The estimates show that our securitization dummy does not reflect a simple time trend. The coefficient of the securitization dummy is negative, statistically significant and in the range of values obtained for our 
full sample period.

We corroborate this finding even if, in addition, we consider the trend in financial integration. The second line of table III displays the corresponding estimates. Financial integration seems to be helpful in improving consumption risk sharing as is mirrored in the negative $\beta_{2}$. It is not significant at the 95 percent but 90 percent confidence level thus supporting Sørensen et al. (2007) and Artis and Hofmann (2008). In addition, the coefficient of $S E C_{t}^{k}$ remains virtually unaltered. Securitization improves international risk sharing. More importantly, this result is independent of the increase in financial integration as measured by gross foreign asset holdings.

For the sake of completeness, the third line of Table III gives the risk sharing coefficient estimates when we consider all three variables jointly while the forth line reports estimates when the interaction of financial integration and securitization is considered. We see some quantitative but no qualitative differences compared to the previous exercises. Both financial integration and securitization of mortgage related risks reduce the amount of unshared idiosyncratic consumption growth risk, but these effects are independent of each other. We do not report estimates of $\gamma_{1}$ as they are insignificant throughout.

\subsection{Securitization and other characteristics of mortgage fi- nance markets}

The structure of mortgage markets differs across countries in many respects. The degree to which securitization is possible is just one of them. Tsatsaronis and Zhu (2004) distinguish between three different groups of OECD countries based on differences in the following dimensions: i) the extent to which securitization of mortgage payments is used, ii) the flexibility of mortgage 
interest rate agreements, iii) the valuation method employed to determine the mortgage lending volume, $i v$ ) the maximum loan-to-value ratio and $v$ ) the use of mortgage equity withdrawal. A couple of countries that have liberalized their secondary markets for mortgage debt also allow for mortgage equity withdrawal. On the other hand, countries that do not allow the securitization of mortgage payments also forbid the use of mortgage equity withdrawal etc. Hence, our securitization dummy could reflect one of the other distinguishing features of national mortgage finance markets.

To alleviate concerns in this respect we take data on mortgage rates (flexible vs. fixed), mortgage equity withdrawal (allowed and used vs. not allowed or not used), maximum loan to valuation ratio and valuation method (historical prices vs. market valuation) from table 2 in Tsatsaronis and Zhu (2004) to construct qualitative measures for all of these different characteristics of mortgage finance systems just as for securitization. ${ }^{9}$ We then parameterize

$$
\beta_{U}(t)=\beta_{0}+\beta_{1} S E C_{t}^{k}+\beta_{2} X_{t}^{k}+\beta_{3} t
$$

with $X_{t}^{k}$ representing one of the qualitative measures of the other mortgage market characteristis such as flexibility of mortgage interest rates $(M R)$, mortgage equity withdrawal $(M E W)$, loan to valuation ratio $(L T V)$ and valuation method $(V M)$. We use the full sample period from 1985Q1 to 2008Q1.

Table IV reports if these different mortgage market characteristics influence risk sharing when considered on their own (in each case the first of the two lines) and, specifically, if the other characteristics drive out the impact

\footnotetext{
${ }^{9}$ Unfortunately, we do not have exact information about the time at which e.g. mortgage equity withdrawal has been allowed in the various countries, such that we have to assume that the differences across countries with regard to the profile of mortgage finance systems prevailed for the whole sample period.
} 
of securitization on international risk sharing (the second line respectively). The results are easily summarized: none of the individual mortgage market characteristics other than securitization is statistically significant. The coefficients are all positive meaning that e.g. more mortgage equity withdrawal is, if anything, associated with less international risk sharing. Securitization seems to be special in this respect.

The second lines in the panels labelled $M R, M E W, L T V$ and $V M$ report the estimates for the case when $S E C_{t}^{k}$ is also included. Most of the other mortgage market features now seem to statistically significantly influence consumption risk sharing, though it may be hard to interpret these coefficients intuitively. However, securitization is always still significant, the coefficient estimate negative and almost unaltered when compared to the previous regressions where $S E C_{t}^{k}$ was the only variable interacted with GDP growth.

The bottom line of the results reported in Table IV is clear: our finding that securitization increases international risk sharing does not seem to be influenced by controls for other characteristics of mortgage markets.

\subsection{Monte Carlo Simulations}

Our results that securitization of mortgage debt increases international risk sharing appears robust to a range of controls for financial globalization, differences in the financial system. However, it is always conceivable that we have neglected other developments that could have affected international risk sharing over the sample period and that our securitization indicator just picks up the cumulative impact of these developments. We therefore conduct a Monte Carlo exercise in which we demonstrate that both the precise timing and the extent to which securitization was allowed matter 
for our results. In the setup of our experiment, we follow Aghion et al. (2008) and Hoffmann and Shcherbakova (2008) and randomly assign securitization indicators to countries. Specifically, for all 16 countries we draw from the empirical distribution of $S E C_{t}^{k}$ to generate a "placebo" measure of the timing and degree of securitization, $S E C_{t}^{P, k}$. We repeat this procedure 1000 times. For each draw, we then perform two checks: first, we run the regression

$$
\Delta \widetilde{c}_{t}^{k}=\beta_{0} \Delta{\widetilde{g d p_{t}}}^{k}+\beta_{1}^{P} S E C_{t}^{P, k} \times \Delta{\widetilde{g d p_{t}}}^{k}+\gamma_{1} S E C_{t}^{P, k}+\alpha+\delta^{k}+\tau_{t}+\varepsilon_{t}^{k}
$$

to check in how many cases $\beta_{1}^{P}$ would be negative and more significant than the actual $S E C_{t}^{k}$. Second, we consider both the placebo and the actual securitization indicator jointly and report in how many cases their regression coefficients are individually negative and significant, i.e.

$$
\Delta \widetilde{c}_{t}^{k}=\beta_{0} \Delta \widetilde{g d p}_{t}^{k}+\beta_{1}^{P} S E C_{t}^{P, k} \times \Delta{\widetilde{g d p_{t}}}^{k}+\beta_{2} S E C_{t}^{k} \times \Delta{\widetilde{g d p_{t}}}^{k}+\alpha+\delta^{k}+\tau_{t}+\varepsilon_{t}^{k}
$$

Panel A of Table V presents the results when we ask about the significance of the placebo indicator. We see that the coefficient of the placebo securitization measure is negative and more significant than the actual measure in no more than about $1.9 \%$ of all cases if taken alone.

Panel $\mathrm{B}$ of table $\mathrm{V}$ displays that when both the placebo and the actual securitization measure are considered jointly, the placebo measure turns out to be individually negatively significant in roughly 4 percent of all draws while the actual securitization measure is significant in 95 percent of all cases. These Monte Carlo simulations thus underscore that our results are not the outcome of pure chance: the extent and the timing at which securitization of mortgage debt has been introduced is crucial in order to identify the impact 
of securitization on international consumption risk sharing. In view of these results it appears highly unlikely that other developments that just broadly unfolded in the same way as the use of mortgage securitization can account for the significance of our main results.

\subsection{Securitization, global asset price cycles and international risk sharing}

The notion we have sought to convey in our analysis is that securitization of mortgage related risks reduces an economy's exposure (in terms of consumption) to idiosyncratic business cycle shocks. Prima facie, this message seems to be disconnected from the current crisis in international financial markets. Policymakers worldwide worry if and to what extent the current swings in global asset prices feed back on the real economy. Furthermore, the trigger of the current crisis were losses on securities that were backed by mortgages to U.S. households with poor or no credit rating.

We make the following remarks: increased international risk sharing inevitably increases the relative importance of global shocks for the volatility of consumption. In fact, the view that securitization of mortgage debt has contributed to turning a national real estate boom into what is the first globalized housing bust is not at all inconsistent with our findings here. For better or for worse it suggests that securitization does help to share the costs of the crisis internationally.

More immediately relevant for our analysis here is however the possibility that the extent to which international risk sharing is possible could itself be subject to variation over time. If securitization facilitates international risk pooling mainly in tranquil periods but risk sharing becomes all but impossible in periods of severe global turbulence, then the potential 
macroeconomic benefits from securitization could be much smaller than is suggested by our previous results.

We address this concern by asking to what extent risk sharing varies as a function of global asset market conditions. We focus on asset prices as indicator of global asset market conditions. The role of asset price fluctuations in driving leverage and liquidity in the recent years (and their role on accelerating the deleveraging process in the current crisis) has been stressed by Adrian and Shin (2008). Lustig and van Nieuwerburgh (2006) point at the importance of real estate prices in explaining collateral availability and the extent of risk sharing among US regions. Hoffmann and Shcherbakova (2008) highlight the importance of stock price movements for risk sharing among U.S. regions. Risk sharing increases in times of high asset prices and decreases in times of low asset prices. Employing the risk sharing regression with interaction terms as we do in this paper, their stand-in for high/low asset prices is the residual of the U.S. consumption-wealth ratio, cay, which is a powerful predictor of expected returns on the U.S. stock market (Lettau and Ludvigson (2001)). Nitschka (2007) shows that U.S. cay can also be used as a forecasting variable of the G7 stock market returns. We repeat this forecasting exercise for stock market excess returns of the countries in our sample and confirm the predictive power of cay: a temporarily high consumption-wealth ratio predicts high future stock market returns.(results not reported but available upon request).

We therefore use cay as proxy for global asset price movements and parameterize the risk sharing coefficient $\beta_{U}(t)$ as

$$
\beta_{U}^{k}(t)=\beta_{0}+\beta_{1} c a y_{t}+\beta_{2} S E C_{t}^{k}+\beta_{3} c a y_{t} \times S E C_{t}^{k}+\beta_{4} t
$$


adding one of the terms on the right hand side at a time. Table VI summarizes the results.

First, we ask if we find dependence of international risk sharing on movements in global asset prices. The answer to this question is yes if we consider the interaction of $c a y_{t}$ with GDP growth on its own. The coefficient $\beta_{1}$ is statistically significant and positive, i.e. high cayt (low asset prices) are associated with less risk sharing. We thus corroborate one of the results in Hoffmann and Shcherbakova (2008) in an international context. Figure 4 further illustrates this result. Here we plot cayt (dashed line) against the sequence of coefficients $\beta_{U}(t)$ (solid line) obtained from the cross-sectional regressions

$$
\Delta \widetilde{c}_{t}^{k}=\beta_{U}(t) \Delta \widetilde{g d p_{t}^{k}}+\tau_{t}+\varepsilon_{t}^{k}
$$

where $\tau_{t}$ is the time $t$ specific constant. Since these cross-sectional estimates of $\beta_{U}(t)$ are very noisy and in order to emphasize the business-cycle frequency movements in risk sharing, we take a 12-quarter moving average of the $\beta_{U}(t)$ coefficients. As is apparent, uninsured consumption risk and cay $_{t}$ move together for most of the sample period (a correlation of 0.64 ): international risk sharing tends to be high when global asst prices are high and vice versa. ${ }^{10}$

Next we additionally consider the interaction of our securitization dummy with idiosyncratic GDP growth. These estimates, reported in the second line

\footnotetext{
${ }^{10} \mathrm{We}$ also explored the possibility that international risk sharing could vary simply because downturns are generally more common than upswings, which could suggest that there is simply less idiosyncratic risk to share in recessions. Since this asymmetry has mainly been documented with respect to the output cycle, we therefore included aggregate GDP growth instead of cay in the set of interaction terms. Unlike cay, however, this variable did not turn out to be significant in the risk sharing regression. The up and down of international risk sharing seems to explained by time-varying frictions in international asset markets - the channel that is our focus here - and not by world business cycle fluctuations per se. We thank Jean Imbs for suggesting this check. Hoffmann and Shcherbakova (2008) investigate the role of aggregate GDP fluctuations for risk sharing among U.S. regions in detail.
} 
of Table VI, convey a clear message. Even if we take account of global asset price fluctuations, securitization of mortgage debt still increases international risk sharing significantly and the order of magnitude of the coefficient on $S E C_{t}^{k}$ remains unchanged.

The third line of Table VI provides estimates when we also take account of a possible interaction between asset price movements and securitization. This specification explicitly allows the sensitivity of risk sharing to global asset market conditions to depend on whether a country has a developed market for securitized mortgage debt. There is no evidence for this. If anything, securitization would seem to lower the dependence of a country's ability to share risk to global asset market conditions - though insignificant, the coefficient $\beta_{3}$ is negative. Note also that the coefficient on cay alone, $\beta_{1}$, now also becomes insignificant. The relation between global asset price movements as echoed in $c_{a} y_{t}$ and international risk sharing essentially breaks down if we also take account of a time trend. In all cases, the securitization coefficient alone, $\beta_{2}$, is virtually unchanged. We conclude from this exercise that international risk sharing does seem to depend on global asset market conditions, increasing in asset price booms and markedly decreasing in downturns. But we do not find that countries with more developed markets for securitization are systematically more or less exposed to this phenomenon.

\section{Conclusions}

The securitization of mortgage related debt improves international risk sharing because it makes the idiosyncratic risks associated with this debt internationally tradeable. The effect is large: for countries with the most developed secondary markets for mortgage-related debt the volatility of consumption 
conditional on an idiosyncratic business cycle shocks is between 20 and 30 percentage points lower than for countries in which such markets do not exist. We find that this result is robust to a range of controls for other aspects of financial globalization and that it is independent of international differences in financial systems, other systematic differences in housing and mortgage markets etc.

Against the backdrop of the current crisis our findings raise the question whether securitization could not just help pooling risks in tranquil times, leaving the possibility that international risk sharing all but dries up in busts. Indeed we find that the extent to which international risk sharing is possible does depend on global asset market conditions: risk sharing increases during asset price booms and decreases sharply in busts. However, even taking account of the most recent downturn (our sample ends in the first quarter of 2008), we do not find evidence that countries with highly developed markets for securitized mortgage debt are necessarily more exposed to the global asset price cycle. These findings are consistent with recent events: they underscore that securitization of mortgage debt was crucial in turning the US subprime crisis into what may well be the first globalized real estate bust. 


\section{References}

[1] Adrian, T. and H. Shin (2008). "Liquidity and Financial Cycles", Bank for International Settlements Working Paper no 256.

[2] Aghion, P. , Burgess, R., Redding, S. and F. Zilibotti, (2008). "The Unequal Effects of Liberalization: Evidence from Dismantling the License Raj in India", American Economic Review 98, 1397-1412

[3] Artis, M.J. and M. Hoffmann (2007), "The Home Bias and Capital Income Flows between Countries and Regions", IEW working paper 316

[4] Artis, M.J. and M. Hoffmann (2008), "Financial Globalization, International Business Cycles and Consumption Risk Sharing", Scandinavian Journal of Economics, 110(3), 447-471.

[5] Asdrubali, P., Sørensen, B. and O. Yosha (1996), "Channels of interstate risk sharing: United States 1963-1990", Quarterly Journal of Economics 111, 1081-1110.

[6] Backus, D. and Smith, G. (1993). "Consumption and Real Exchange Rates in Dynamic Exchange Economies with Nontraded Goods" Journal of International Economics 35, 297-316.

[7] Brunnermeier, Marcus (2008). "Deciphering the 2007-08 Liquidity and Credit Crunch", Journal of Economic Perspectives, 2008 (forthcoming)

[8] Cochrane, J.H. (1991), "A simple test of consumption insurance", Journal of Political Economy 99, 957-976.

[9] Crucini, M. (1999), On international and national dimensions of risk sharing, The Review of Economics and Statistics 81(1), 73-84.

[10] Demyanyk, Y. , Ostergaard, C. and B. Sørensen (2007), "U.S. Banking Deregulation, Small Businesses, and Interstate Insurence of Personal Income", Journal of Finance 62, 2763-2801.

[11] Demyanyk, Y. and O. Van Hemert (2008). "Understanding the Subprime Mortgage Crisis", Federal Reserve Bank of St. Louis, Supervisory Policy Analysis Working Paper 2007/05 (draft is dated August 2008). 
[12] European Central Bank (2003), "Structural Factors in the EU housing markets", ECB March 2003.

[13] Girouard, N. and S. Blöndal (2001), "House Prices and Economic Activity", OECD Economics Department Working Paper No. 279.

[14] Hoffmann, M. (2008), "The Lack of International Consumption Risk Sharing: Can Inflation Differentials and Trading Costs Help Explain the Puzzle?", Open Economies Review 19, 183-201

[15] Hoffmann, M. and I. Shcherbarkova (2008), "Consumption Risk Sharing over the Business Cycle: The Role of Small Firms' Access to Credit Markets", IEW working paper 363.

[16] Imbs, J. (2006), "The Real Effect of Financial Globalization", Journal of International Economics 68, 296-234.

[17] Keys, B. J.,Mukherjee, T. , Seru, A. and V. Vig (2008). "Did Securitization Lead to Lax Screening? Evidence from Subprime Loans", manuscript University of Michigan dated April 2008.

[18] Lane, P. and G.M. Milesi-Ferretti (2001), "The External Wealth of Nations: Measures of Foreign Assets and Liabilities for Industrial and Developing Nations", Journal of International Economics 55, 263-294.

[19] Lane, P. and G.M. Milesi-Ferretti (2003), "International Financial Integration", IMF staff papers

[20] Lane, P. and G.M. Milesi-Ferretti (2007), "The external wealth of nations mark II: Revised and extend estimates of foreign assets and liabilities, 1970-2004", Journal of International Economics 73, 223-250.

[21] Loutskina, E. and P. E. Strahan (2009). "Securitization and the Declining Impact of Bank Finance on Loan Supply: Evidence from Mortgage Originations", forthcoming in the Journal of Finance.

[22] Lettau, M. and S. Ludvigson (2001), "Consumption, Aggregate Wealth and Expected Stock Returns", Journal of Finance 56, 815-849.

[23] Lustig, H. and S. van Nieuwerburgh (2005), "Housing Collateral, Consumption Insurance and Risk Premia", Journal of Finance 60, 11671219 . 
[24] Lustig, H. and S. van Nieuwerburgh (2006), "How much does Household Collateral constrain Regional Risk Sharing?", working paper UCLA and NYU Stern

[25] Mace, B. (1991) "Full Insurance in the Presence of Aggregate Uncertainty", Journal of Polical Economy 99, 928-956.

[26] Mian, A. and A. Sufi (2008). "The Consequences of Mortgage Credit Expansion: Evidence from the 2007 Mortgage Default Crisis", NBER working paper 13936 .

[27] Newey W.K. and K.W. West (1987) "A simple, positive semidefinite, heteroskedasticity and autocorrelation consistent covariance matrix", Econometrica 55, 703-708.

[28] Nitschka, T. (2007), "International evidence for return predictability and the implications for long-run covariation of the G7 stock markets", IEW working paper 338

[29] Sørensen, B.,Yosha, O., Wu, Y.-T. and Zu, Y. (2007), "Home Bias and International Risk Sharing: Twin Puzzles Separated at Birth", Journal of International Money and Finance, 26, 587-625.

[30] Sørensen, B. and O. Yosha (1998), "International Risk Sharing and European Monetary Unification", Journal of International Economics 45, 211-238.

[31] Townsend, R.M. (1994), "Risk and insurance in Village India", Econometrica 62, 539-591.

[32] Tsatsaronis, K. and H. Zhu (2004), "What drives housing price dynamics: cross-country evidence" BIS Quarterly Review March 


\section{Appendix: Results based on securitization ratios}

The main part of our analysis has relied on a qualitative measure of the extent of securitization. This was partly due to the lack of appropriate data for the countries and time series under study. Ideally, one would like to have information about the amount outstanding of mortgage backed securities and relate them to the amount of outstanding mortgages in an economy. Only recently, the Securities Industry and Financial Markets Association (SIFMA) started to collect data on issuance of asset backed securities. Therefore, we do our best to calculate actual measures of the degree of securitization. We use national sources to obtain such admittedly crude mortgage securitization ratios for the United States, Australia, Germany and Switzerland.

The U.S. Flow of Fund Accounts provide information about the amount outstanding of mortgages used to back securities. We take the ratio of this number with the amount of outstanding home mortgages in U.S. households' balance sheets as proxy for the degree of securitization. The Federal Reserve Bank of Australia gives similar information but for new issues of mortgages and mortgage backed securities such that the Australian securitization ratio is calculated in basically the same way. Furthermore, the Deutsche Bundesbank publishes data on the total amount outstanding of issued bonds and bonds covered by mortgages (Hypothekenpfandbriefe). The respective ratio gives the degree of mortgage securitization in Germany. The Swiss National Bank publishes new issues of mortgage covered bonds and of the total amount of bonds. Again the ratio is used as indicator of the degree of securitization. Together with the five countries that do not allow for mortgage securitization we run our basic risk sharing regression for this smaller panel of nine countries for the time period from 1985Q1 to 2008Q1. Table A.IV reports the results.

Panel A of Table A.IV provides the corresponding estimates if we use our qualitative measure of securitization taking account of a time trend interaction with GDP. These estimates just reproduce our main results for ease of comparison.

Panel B displays the corresponding results for our actual mortgage securitization proxy. The corresponding interaction coefficient is large, negative but not significant at the $95 \%$ confidence level with a t-statistic of 1.57 (the $\mathrm{p}$-value is 0.14 ). 
Our measure of actual securitization is a very crude one as the data is not internationally comparable: First, we have outstanding debt for some countries and only new issues for others. ${ }^{11}$ Secondly, as we have discussed in the main text, the de-facto measures will not capture the extent to which securitized mortgage debt issued in different countries represents a different asset with different legal implications for issuers and buyers and therefore for risk sharing. In spite of these limitations of the de facto measure, our results here still convey the notion that securitization contributes to better international risk sharing.

\footnotetext{
${ }^{11}$ For those countries for which we only have new issues, we tried to obtain stocks through the application of a 'perpetucal inventory method', assuming that 20 percent of the outstanding debt gets repaid every year. Doing so did not affect the results, but clearly the cumulated stocks would also be very imprecisely measured.
} 
Table I: Securitization and international risk sharing

The table displays the estimates from our baseline risk sharing regression:

$\Delta \widetilde{c}_{t}^{k}=\beta_{0} \Delta{\widetilde{g d p_{t}}}^{k}+\beta_{1} S E C_{t}^{k} \times \Delta{\widetilde{g d p_{t}}}^{k}+\gamma_{1} S E C_{t}^{k}+\alpha+\delta^{k}+\tau_{t}+\varepsilon_{t}^{k}$

where $\Delta \widetilde{c}_{t}^{k}$ denotes idiosyncratic consumption growth, ${\widetilde{\Delta g d p_{t}}}^{k}$ idiosyncratic GDP growth

and $S E C_{t}^{k}$ is a qualitative measure that indicates when and to what extent country $k$

has introduced the securitization of mortgage payments. Robust t-statistics (Newey and West

(1987)) are in parentheses below the estimates.

Baseline regression:

$\Delta \widetilde{c}_{t}^{k}=\beta_{0} \Delta \widetilde{g d p}_{t}^{k}+\beta_{1} S E C_{t}^{k} \times \Delta \widetilde{g d p}_{t}^{k}+\gamma_{1} S E C_{t}^{k}+\alpha+\delta^{k}+\tau_{t}+\varepsilon_{t}^{k}$

Panel A: 1985Q1 - 2008Q1

$\beta_{0} \quad \beta_{1}$

$\begin{array}{lll}0.79 & -0.35 & 0.00\end{array}$

$\begin{array}{lll}(32.30) & (-4.70) & (0.04)\end{array}$

Panel B: 1995Q1 - 2008Q1

$\begin{array}{ccc}\beta_{0} & \beta_{1} & \gamma_{1} \\ 0.80 & -0.58 & -0.00 \\ (23.38) & (-6.01) & (-0.00)\end{array}$

Panel C: 1985Q1 - 1996Q4

$\begin{array}{ccc}\beta_{0} & \beta_{1} & \gamma_{1} \\ 0.81 & -0.23 & -0.00 \\ (26.08) & (-2.22) & (-0.00)\end{array}$


Table II: Risk sharing in high/low securitization countries

We sort the 16 countries under study into three bins according to their level of securitization $S E C_{t}^{k}$ at time $t$. We repeat this sorting procedure every quarter for the time period from 1985Q1 to $2008 \mathrm{Q} 1$ such that we obtain synthetic low, middle and high securitization country panels. Since $S E C_{t}^{k}$ is a qualitative measure, it is possible that there are ties in this sorting procedures (e.g. at a given point in time, there may be more than a quarter of countries that have the lowest degree of securitization $S E C_{t}^{k}=0$.). We resolve such ties through randomization as described in the main text. Then we run the risk sharing regression. $\Delta \widetilde{c}_{t}^{k}=$ $\beta_{U} \Delta{\widetilde{g d p_{t}}}^{k}+\alpha+\delta^{k}+\tau_{t}+\varepsilon_{t}^{k}$ for the first quartile (low securitization) and fourth quartile (high securitization). To ascertain that random assignment to bins in the case of ties does not affect our results, we repeated this exercise 100 times to obtain an entire series of risk sharing coefficients, $\beta_{U}$. The table reports averages of these risk sharing coefficients. Average Newey-West corrected t-statistics (Newey and West (1987)) over these 100 draws are in parentheses.

\begin{tabular}{cc}
\hline \hline Low securitization & High securitization \\
\hline$\beta_{U}$ & $\beta_{U}$ \\
0.77 & 0.60 \\
$(23.44)$ & $(16.31)$ \\
\hline
\end{tabular}


Table III: Trend in financial integration and securitization

The table presents estimates from the regression:

$$
\Delta \widetilde{c}_{t}^{k}=\beta_{0} \Delta \widetilde{g d p_{t}^{k}}+\mathbf{z}_{t}^{k \prime} \boldsymbol{\beta}_{z} \Delta \widetilde{g d p_{t}^{k}}+\mathbf{y}_{t}^{k \prime} \gamma+\alpha+\delta^{k}+\tau_{t}+\varepsilon_{t}^{k}
$$

with the parameterization

$\beta_{U}^{k}(t):=\beta_{0}+\mathbf{z}_{t}^{k \prime} \boldsymbol{\beta}_{z}=\beta_{0}+\beta_{1} S E C_{t}^{k}+\beta_{2} g f a_{t}+\beta_{3} g f a_{t} \times S E C_{t}^{k}+\beta_{4} t$

where $g f a_{t}=\sum_{k=1}^{16} \frac{\left(F A_{k t}+F L_{k t}\right)}{G D P_{k t}}$ with $F A_{k t}$ gross foreign assets of country $k$ at time

$t$ and $F L_{k t}$ gross foreign liabilities of country $k$ at time $t$. It thus summarizes the gross

foreign asset positions of the countries under study relative to GDP. Robust t-statistics (Newey

and West (1987)) appear in parentheses below the estimates. The sample period runs from

$1985 \mathrm{Q} 1$ to $2004 \mathrm{Q} 4$

sample period: 1985Q1 - 2004Q4

\begin{tabular}{|c|c|c|c|c|}
\hline \multicolumn{5}{|c|}{ interaction of $\Delta \widetilde{g d p}_{+}^{k}$ with } \\
\hline $\begin{array}{c}1 \\
\left(\beta_{0}\right)\end{array}$ & $\begin{array}{c}S E C_{t}^{k} \\
\left(\beta_{1}\right)\end{array}$ & $\begin{array}{l}g f a_{t} \\
\left(\beta_{2}\right)\end{array}$ & $\begin{array}{c}g f a_{t} \times S E C_{t}^{k} \\
\left(\beta_{3}\right)\end{array}$ & $\begin{array}{c}t \\
\left(\beta_{4}\right)\end{array}$ \\
\hline $\begin{array}{c}0.79 \\
(16.35)\end{array}$ & $\begin{array}{l}-0.33 \\
(-2.43)\end{array}$ & & & $\begin{array}{l}-0.00 \\
(-1.10)\end{array}$ \\
\hline $\begin{array}{c}0.79 \\
(16.35)\end{array}$ & $\begin{array}{l}-0.33 \\
(-2.39)\end{array}$ & $\begin{array}{l}-0.10 \\
(-1.86)\end{array}$ & & \\
\hline $\begin{array}{c}0.80 \\
(16.92)\end{array}$ & $\begin{array}{l}-0.38 \\
(-2.68)\end{array}$ & $\begin{array}{l}-0.13 \\
(-2.15)\end{array}$ & & $\begin{array}{l}0.00 \\
(0.82)\end{array}$ \\
\hline $\begin{array}{c}0.81 \\
(17.47)\end{array}$ & $\begin{array}{l}-0.36 \\
(-2.68)\end{array}$ & $\begin{array}{l}-0.43 \\
(-2.18)\end{array}$ & $\begin{array}{l}-0.41 \\
(-1.81)\end{array}$ & $\begin{array}{c}0.01 \\
(2.28)\end{array}$ \\
\hline
\end{tabular}


Table IV: Securitization and other mortgage market profiles

The table presents estimates from the regression

$$
\Delta \widetilde{c}_{t}^{k}=\beta_{0} \Delta \widetilde{g d p_{t}^{k}}+\mathbf{z}_{t}^{k \prime} \boldsymbol{\beta}_{z} \Delta \widetilde{g d p_{t}^{k}}+\mathbf{y}_{t}^{k \prime} \gamma+\alpha+\delta^{k}+\tau_{t}+\varepsilon_{t}^{k}
$$

with the parameterization

$$
\beta_{U}^{k}(t):=\beta_{0}+\mathbf{z}_{t}^{k \prime} \boldsymbol{\beta}_{z}=\beta_{0}+\beta_{1} S E C_{t}^{k}+\beta_{2} X_{t}^{k}+\beta_{3} t
$$

with $X_{t}^{k}$ representing one of the dummys of the other mortgage market characteristis such as flexibility of mortgage interest rates $(M R)$, mortgage equity withdrawal ( $M E W$ ), loan to valuation ratio $(L T V)$ and valuation method $(V M)$. Robust t-statistics (Newey and West (1987)) appear in parentheses below the estimates. The sample period runs from $1985 \mathrm{Q} 1$ to

\begin{tabular}{|c|c|c|c|c|}
\hline \multicolumn{5}{|c|}{ sample period: 1985Q1 - 2008Q1 } \\
\hline & \multicolumn{4}{|c|}{ Interaction of ${\widetilde{\Delta g d p_{t}}}^{k}$ with } \\
\hline$X$ & $\begin{array}{c}1 \\
\left(\beta_{0}\right)\end{array}$ & $\begin{array}{c}S E C_{t}^{k} \\
\left(\beta_{1}\right)\end{array}$ & $\begin{array}{c}X^{k} \\
\left(\beta_{2}\right)\end{array}$ & $\begin{array}{c}t \\
\left(\beta_{3}\right)\end{array}$ \\
\hline \multirow[t]{2}{*}{$M R$} & $\begin{array}{c}0.67 \\
(19.41)\end{array}$ & & $\begin{array}{l}0.06 \\
(1.30)\end{array}$ & \\
\hline & $\begin{array}{c}0.72 \\
(19.72)\end{array}$ & $\begin{array}{l}-0.34 \\
(-4.42)\end{array}$ & $\begin{array}{c}0.09 \\
(1.85)\end{array}$ & $\begin{array}{l}-0.00 \\
(-2.45)\end{array}$ \\
\hline \multirow[t]{2}{*}{$M E W$} & $\begin{array}{c}0.64 \\
(13.82)\end{array}$ & & $\begin{array}{l}0.08 \\
(1.67)\end{array}$ & \\
\hline & $\begin{array}{c}0.68 \\
(14.24)\end{array}$ & $\begin{array}{l}-0.33 \\
(-4.35)\end{array}$ & $\begin{array}{l}0.21 \\
(2.21)\end{array}$ & $\begin{array}{l}-0.00 \\
(-2.65)\end{array}$ \\
\hline \multirow[t]{2}{*}{$L T V$} & $\begin{array}{l}0.61 \\
(9.69)\end{array}$ & & $\begin{array}{c}0.13 \\
(1.63)\end{array}$ & \\
\hline & $\begin{array}{c}0.64 \\
(10.21)\end{array}$ & $\begin{array}{l}-0.34 \\
(-4.47)\end{array}$ & $\begin{array}{l}0.17 \\
(2.27)\end{array}$ & $\begin{array}{l}-0.00 \\
(-2.51)\end{array}$ \\
\hline \multirow[t]{2}{*}{$V M$} & $\begin{array}{l}0.49 \\
(3.45)\end{array}$ & & $\begin{array}{l}0.25 \\
(1.64)\end{array}$ & \\
\hline & $\begin{array}{l}0.47 \\
(3.47)\end{array}$ & $\begin{array}{l}-0.34 \\
(-4.48)\end{array}$ & $\begin{array}{l}0.35 \\
(2.28)\end{array}$ & $\begin{array}{l}-0.00 \\
(-2.50)\end{array}$ \\
\hline
\end{tabular}
$2008 \mathrm{Q} 1$. 


\section{Table V: Monte Carlo Simulations}

This table provides evidence from a Monte Carlo experiment in which we randomly assign the values that indicate the degree of securitization to each country. We draw from the empirical distribution of $S E C_{t}^{k}$ and repeat this procedure 1000 times to generate a "placebo" measure of the timing and degree of securitization, $S E C_{t}^{P, k}$. First, we run

$\Delta \widetilde{c}_{t}^{k}=\beta_{0} \Delta \widetilde{g d p}_{t}^{k}+\beta_{1}^{P} S E C_{t}^{P, k} \times \Delta{\widetilde{g d p_{t}}}^{k}+\gamma_{1} S E C_{t}^{P, k}+\alpha+\delta^{k}+\tau_{t}+\varepsilon_{t}^{k}$ to check in how many cases $\beta_{1}^{P}$ would be negative and more significant as the actual $S E C_{t}^{k}$. Second, we regard both the placebo and the actual securitization dummy jointly and report in how many cases their regression coefficients are individually negative and significant according to Newey and West corrected t-statistics (Newey and West (1987)), i.e.

$$
\Delta \widetilde{c}_{t}^{k}=\beta_{0} \Delta{\widetilde{g d p_{t}}}^{k}+\beta_{1}^{P} S E C_{t}^{P, k} \times \Delta{\widetilde{g d p_{t}}}^{k}+\beta_{2} S E C_{t}^{k} \times{\widetilde{g d p_{t}}}^{k}+\alpha+\delta^{k}+\tau_{t}+\varepsilon_{t}^{k}
$$

Panel A gives the percentage of cases in which we find significant estimates of the first exercise, panel B provides the results for the second exercise.

\begin{tabular}{ccc}
\hline \hline Panel A: $\beta_{U}(t)=\beta_{0} \Delta{\widetilde{g d p_{t}}}^{k}+\beta_{1}^{P} S E C_{t}^{P, k} \times \Delta{\widetilde{\sigma d p_{t}}}^{k}+\gamma_{1} S E C_{t}^{P, k}$ \\
\hline$\beta_{0}$ & $\beta_{1}^{P}$ & $\gamma_{1}$ \\
$100 \%$ & $1.9 \%$ & $0 \%$ \\
\hline Panel B: $\beta_{U}(t)=\beta_{0} \Delta{\widetilde{g d p_{t}}}^{k}+\beta_{1}^{P} S E C_{t}^{P, k} \times \Delta \widetilde{g d p}_{t}^{k}+\beta_{2} S E C_{t}^{k} \times \Delta \widetilde{g d p}_{t}^{k}$ \\
\hline$\beta_{0}$ & $\beta_{1}^{P}$ & $\beta_{2}$ \\
$100 \%$ & $4.1 \%$ & $95 \%$
\end{tabular}


Table VI: Risk sharing, cay and securitisation

The table presents results from the regression:

$$
\Delta \widetilde{c}_{t}^{k}=\beta_{0} \Delta{\widetilde{g d p_{t}}}^{k}+\mathbf{z}_{t}^{k \prime} \boldsymbol{\beta}_{z} \Delta \widetilde{g d p_{t}^{k}}+\mathbf{y}_{t}^{k \prime} \boldsymbol{\gamma}+\alpha+\delta^{k}+\tau_{t}+\varepsilon_{t}^{k}
$$

with the parameterization

$\beta_{U}^{k}(t):=\beta_{0}+\mathbf{z}_{t}^{k \prime} \boldsymbol{\beta}_{z}=\beta_{0}+\beta_{1} c a y_{t}+\beta_{2} S E C_{t}^{k}+\beta_{3} c a y_{t} \times S E C_{t}^{k}+\beta_{4} t$

where " $t$ " denotes a time trend, $S E C_{t}^{k}$ is a dummy that indicates when and qualitatively

to what extent countries in our sample allowed the securitisation of mortgages. The variable

$c a y_{t}$ is the residual from the cointegration relation between consumption, asset wealth and labour income in the U.S. freely available on Martin Lettau's website. Our panel regression estimates are obtained for the time period from 1985Q1 - 2008Q1. Robust t-statistics (NeweyWest (1987)) appear below the estimates in parentheses.

\begin{tabular}{|c|c|c|c|c|}
\hline \multicolumn{5}{|c|}{ sample period:1985Q1 - 2008Q1 } \\
\hline \multicolumn{5}{|c|}{ interaction of $\Delta \widetilde{g d p}_{t}^{k}$ with } \\
\hline 1 & cayt $_{t}$ & $S E C_{t}^{k}$ & $\operatorname{cay}_{t} \times S E C_{t}^{k}$ & $t$ \\
\hline$\left(\beta_{0}\right)$ & $\left(\beta_{1}\right)$ & $\left(\beta_{2}\right)$ & $\left(\beta_{3}\right)$ & $\left(\beta_{4}\right)$ \\
\hline $\begin{array}{c}0.70 \\
(20.73)\end{array}$ & $\begin{array}{l}2.56 \\
(2.53)\end{array}$ & & & \\
\hline $\begin{array}{c}0.77 \\
(21.36)\end{array}$ & $\begin{array}{l}2.38 \\
(2.17)\end{array}$ & $\begin{array}{l}-0.35 \\
(-4.63)\end{array}$ & & \\
\hline $\begin{array}{c}0.77 \\
(20.73)\end{array}$ & $\begin{array}{l}2.34 \\
(1.52)\end{array}$ & $\begin{array}{l}-0.35 \\
(-4.51)\end{array}$ & $\begin{array}{l}0.18 \\
(0.04)\end{array}$ & \\
\hline $\begin{array}{c}0.77 \\
(20.53)\end{array}$ & $\begin{array}{l}1.24 \\
(0.74)\end{array}$ & $\begin{array}{l}-0.32 \\
(-4.13)\end{array}$ & $\begin{array}{l}-0.03 \\
(-0.13)\end{array}$ & $\begin{array}{l}-0.00 \\
(-1.57)\end{array}$ \\
\hline
\end{tabular}


Table A.I : Trend in financial integration (equity) and securitization

This table presents estimates from the regression:

$$
\Delta \widetilde{c}_{t}^{k}=\beta_{0} \Delta \widetilde{g d p_{t}^{k}}+\mathbf{z}_{t}^{k \prime} \boldsymbol{\beta}_{z} \Delta \widetilde{g d p_{t}^{k}}+\mathbf{y}_{t}^{k \prime} \gamma+\alpha+\delta^{k}+\tau_{t}+\varepsilon_{t}^{k}
$$

with the parameterization

$$
\begin{gathered}
\beta_{U}^{k}(t)=\beta_{0}+\beta_{1} S E C_{t}^{k}+\beta_{2} g e q_{t}+\beta_{3} g e q_{t} \times S E C_{t}^{k}+\beta_{4} t \\
\text { where } g e q_{t}=\sum_{k=1}^{16} \frac{\left(P E Q A_{t}^{k}+P E Q L_{t}^{k}+F D I A_{t}^{k}+F D I L_{t}^{k}\right.}{G D P_{t}^{k}} \text { with } P E Q A_{t}^{k} \text { and } P E Q L_{t}^{k}
\end{gathered}
$$

portfolio equity assets and liabilities of country $k_{\text {at time }} t_{\text {and }} F D I A_{t}^{k}$ as well as $F D I L_{t}^{k}$

foreign direct investments on asset and liability side of country $k$ at time $t$. It thus summa-

rizes the gross equity positions of the countries under study relative to GDP. Robust t-statistics

(Newey and West (1987)) appear in parentheses below the estimates. The sample period runs from $1985 \mathrm{Q} 1$ to $2004 \mathrm{Q} 4$.

sample period: 1985Q1 - 2004Q4

interaction of $\widetilde{\Delta d p_{t}^{k}}$ with

\begin{tabular}{ccccc}
1 & $S E C_{t}^{k}$ & $g e q_{t}$ & $g e q_{t} \times S E C_{t}^{k}$ & $t$ \\
$\left(\beta_{0}\right)$ & $\left(\beta_{1}\right)$ & $\left(\beta_{2}\right)$ & $\left(\beta_{3}\right)$ & $\left(\beta_{4}\right)$ \\
\hline 0.79 & -0.33 & & & -0.00 \\
$(16.35)$ & $(-2.43)$ & & & $(-1.10)$ \\
& & & & \\
0.79 & -0.33 & -0.10 & & \\
$(16.41)$ & $(-2.40)$ & $(-1.75)$ & & 0.01 \\
& & & & \\
0.81 & -0.38 & -0.47 & & \\
$(17.09)$ & $(-2.60)$ & $(-2.73)$ & & 0.01 \\
& & & & \\
0.81 & -0.35 & -0.33 & -0.48 & \\
$(16.95)$ & $(-2.40)$ & $(-1.82)$ & $(-2.09)$ & \\
& & & &
\end{tabular}


Table A.II: Financial integration and securitization (variation across countries)

This table presents estimates from the regression

$$
\Delta \widetilde{c}_{t}^{k}=\beta_{0} \Delta \widetilde{g d p_{t}^{k}}+\mathbf{z}_{t}^{k \prime} \boldsymbol{\beta}_{z} \Delta \widetilde{g d p_{t}^{k}}+\mathbf{y}_{t}^{k \prime} \gamma+\alpha+\delta^{k}+\tau_{t}+\varepsilon_{t}^{k}
$$

with the parameterization

$\beta_{U}^{k}(t):=\beta_{0}+\mathbf{z}_{t}^{k \prime} \boldsymbol{\beta}_{z}=\beta_{0}+\beta_{1} S E C_{t}^{k}+\beta_{2} g f a_{t}^{k}+\beta_{3} g f a_{t}^{k} \times S E C_{t}^{k}+\beta_{4} t$

where $g f a_{t}^{k}=\frac{\left(F A_{k t}+F L_{k t}\right)}{G D P_{k t}}$ with $F A_{k t}$ gross foreign assets of country $k$ at time

$t$ and $F L_{k t}$ gross foreign liabilities of country $k$ at time $t$. It thus takes into account the

variation in the gross foreign asset positions of the countries under study relative to GDP.

Robust t-statistics (Newey and West (1987)) appear in parentheses below the estimates. The

sample period runs from $1985 \mathrm{Q} 1$ to $2004 \mathrm{Q} 4$.

\begin{tabular}{|c|c|c|c|c|}
\hline \multicolumn{5}{|c|}{ sample period: $1985 \mathrm{Q} 1-2004 \mathrm{Q} 4$} \\
\hline \multicolumn{5}{|c|}{ interaction of $\widetilde{\Delta g d p}_{t}^{k}$ with } \\
\hline 1 & $S E C_{t}^{k}$ & $g f a_{t}^{k}$ & $g f a_{t}^{k} \times S E C_{t}^{k}$ & $t$ \\
\hline$\left(\beta_{0}\right)$ & $\left(\beta_{1}\right)$ & $\left(\beta_{2}\right)$ & $\left(\beta_{3}\right)$ & $\left(\beta_{4}\right)$ \\
\hline $\begin{array}{c}0.79 \\
(16.35)\end{array}$ & $\begin{array}{l}-0.33 \\
(-2.43)\end{array}$ & & & $\begin{array}{l}-0.00 \\
(-1.10)\end{array}$ \\
\hline $\begin{array}{c}0.87 \\
(12.88)\end{array}$ & $\begin{array}{l}-0.36 \\
(-2.80)\end{array}$ & $\begin{array}{c}-0.06 \\
(--2.99)\end{array}$ & & \\
\hline $\begin{array}{c}0.87 \\
(11.63)\end{array}$ & $\begin{array}{l}-0.37 \\
(-2.61)\end{array}$ & $\begin{array}{l}-0.06 \\
(-2.66)\end{array}$ & & $\begin{array}{l}0.00 \\
(0.08)\end{array}$ \\
\hline $\begin{array}{c}0.81 \\
(17.47)\end{array}$ & $\begin{array}{l}-0.27 \\
(-1.94)\end{array}$ & $\begin{array}{l}-0.05 \\
(-1.95)\end{array}$ & $\begin{array}{l}-0.07 \\
(-0.95)\end{array}$ & $\begin{array}{l}0.00 \\
(0.15)\end{array}$ \\
\hline
\end{tabular}


Table A.III : Financial integration and securitization (equity-based, variation across countries)

This table presents estimates from the regression:

$$
\Delta \widetilde{c}_{t}^{k}=\beta_{0} \Delta \widetilde{g d p}_{t}^{k}+\mathbf{z}_{t}^{k \prime} \boldsymbol{\beta}_{z} \Delta \widetilde{g d p_{t}^{k}}+\mathbf{y}_{t}^{k \prime} \gamma+\alpha+\delta^{k}+\tau_{t}+\varepsilon_{t}^{k}
$$

with the parameterization

$\beta_{U}^{k}(t):=\beta_{0}+\beta_{0}+\mathbf{z}_{t}^{k \prime} \boldsymbol{\beta}_{z}=\beta_{0}+\beta_{1} S E C_{t}^{k}+\beta_{2} g e q_{t}^{k}+\beta_{3} g e q_{t}^{k} \times S E C_{t}^{k}+\beta_{4} t$

$\underset{\text { where geq }}{k}=\frac{\left(P E Q A_{t}^{k}+P E Q L_{t}^{k}+F D I A_{t}^{k}+F D I L_{t}^{k}\right.}{G D P_{t}^{k}}$ with PEQA ${ }_{t}^{k}$ and PEQL ${ }_{t}^{k}$ portfolio equity assets and liabilities of country $\mathrm{k}$ at time $\mathrm{t}$ and FDIA $t$ as well as FDIL $t$ foreign direct investments on asset and liability side of country k at time t. It thus takes into account variation in the gross equity positions of the countries under study relative to GDP. Robust t-statistics (Newey and West (1987)) appear in parentheses below the estimates. The sample period runs from $1985 \mathrm{Q} 1$ to $2004 \mathrm{Q} 4$.

sample period: 1985Q1 - 2004Q4

interaction of $\widetilde{\Delta g d p_{t}^{k}}$ with

\begin{tabular}{ccccc}
1 & $S E C_{t}^{k}$ & $g e q_{t}^{k}$ & $g e q_{t}^{k} \times S E C_{t}^{k}$ & $t$ \\
$\left(\beta_{0}\right)$ & $\left(\beta_{1}\right)$ & $\left(\beta_{2}\right)$ & $\left(\beta_{3}\right)$ & $\left(\beta_{4}\right)$ \\
\hline 0.79 & -0.33 & & & -0.00 \\
$(16.35)$ & $(-2.43)$ & & & $(-1.10)$ \\
& & & & \\
0.83 & -0.27 & -0.13 & & \\
$(15.52)$ & $(-2.13)$ & $(-3.18)$ & & 0.00 \\
& & & & \\
0.83 & -0.27 & -0.15 & & \\
$(13.83)$ & $(-2.13)$ & $(-2.38)$ & & 0.00 \\
& & & & $(0.38)$ \\
0.82 & -0.20 & -0.21 & -0.41 & \\
$(12.18)$ & $(-1.47)$ & $(-0.90)$ & $(-1.81)$ &
\end{tabular}




\section{Table A.IV: Actual securitization measure}

Panel A of this table displays the results from our baseline risk sharing regression:

$$
\Delta \widetilde{c}_{t}^{k}=\beta_{0} \Delta{\widetilde{g d p_{t}}}^{k}+\beta_{1} S E C_{t}^{k} \times \Delta{\widetilde{g d p_{t}}}^{k}+\beta_{2} t \times \Delta{\widetilde{g d p_{t}}}^{k}
$$

where $\Delta \widetilde{c}_{t}^{k}$ denotes idiosyncratic consumption growth, $\widetilde{\Delta d p_{t}}$ idiosyncratic GDP growth and $S E C_{t}^{k}$ is a qualitative measure that indicates when and to what extent country $k$ has introduced the securitization of mortgage payments. The countries under study are: Australia, Belgium, Denmark, Germany, Italy, Japan, Norway, Switzerland and the United States. Robust t-statistics (Newey and West (1987)) are in parentheses below the estimates. The sample period runs from 1985Q1 to 2008Q1. Panel B provides the corresponding results if we construct an approximation of the degree of securitization based on actual data, $S E C_{t}^{k, a c t}$. Details on the construction of $S E C_{t}^{k, a c t}$ are provided in the appendix.

\begin{tabular}{|c|c|c|}
\hline \multicolumn{3}{|c|}{ Panel A: qualitative securitization measure $\left(S E C_{t}^{k}\right)$} \\
\hline \multicolumn{3}{|c|}{ interaction of $\Delta \widetilde{g d p}_{t}^{k}$ with } \\
\hline 1 & $S E C_{t}^{k}$ & $t$ \\
\hline$\left(\beta_{0}\right)$ & $\left(\beta_{1}\right)$ & $\left(\beta_{2}\right)$ \\
\hline $\begin{array}{c}0.73 \\
(25.06)\end{array}$ & $\begin{array}{l}-0.38 \\
(-2.19)\end{array}$ & $\begin{array}{l}-0.00 \\
(-2.55)\end{array}$ \\
\hline \multicolumn{3}{|c|}{ Panel B: actual securitization measure $\left(S E C_{t}^{k, a c t}\right)$} \\
\hline \multicolumn{3}{|c|}{ interaction of $\Delta \widetilde{g d p}_{t}^{k}$ with } \\
\hline 1 & $S E C_{t}^{k, a c}$ & $t$ \\
\hline$\left(\beta_{0}\right)$ & $\left(\beta_{1}\right)$ & $\left(\beta_{2}\right)$ \\
\hline $\begin{array}{c}0.73 \\
(24.76)\end{array}$ & $\begin{array}{l}-1.27 \\
(-1.57)\end{array}$ & $\begin{array}{l}-0.00 \\
(-2.57)\end{array}$ \\
\hline
\end{tabular}




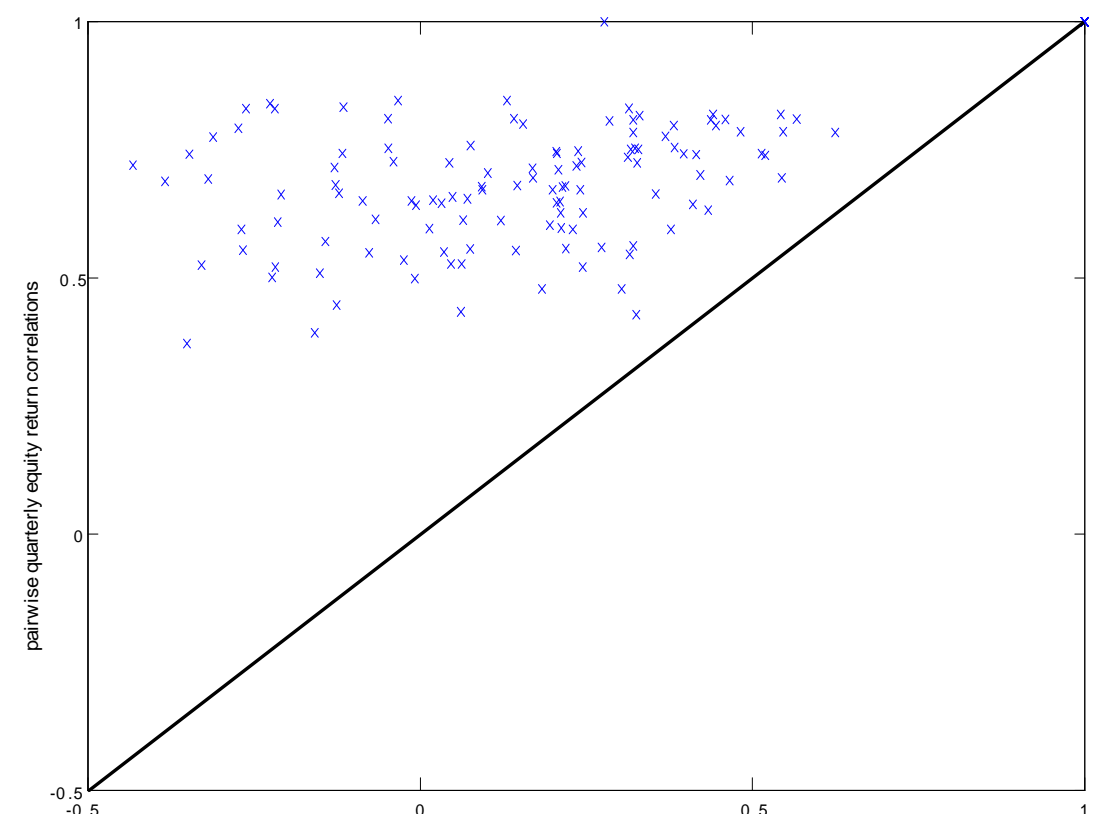

Figure 1: Pairwise correlations of quarterly housing and equity returns for the 16 industrialized countries under study. The sample period is 1985Q1:2008Q1. The black line is the 45-degree line. 


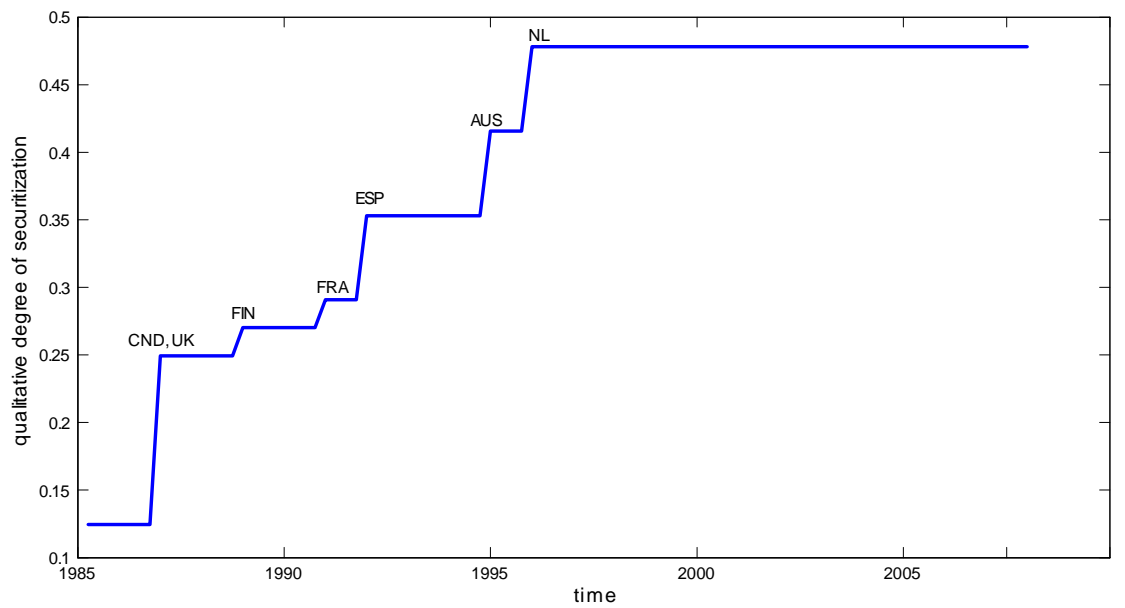

Figure 2: Trend in the qualitative degree of securitization over the sample period from 1985Q1 to 2008Q1. Country acronyms indicate which countries introduced mortgage securitization at the respective date. 


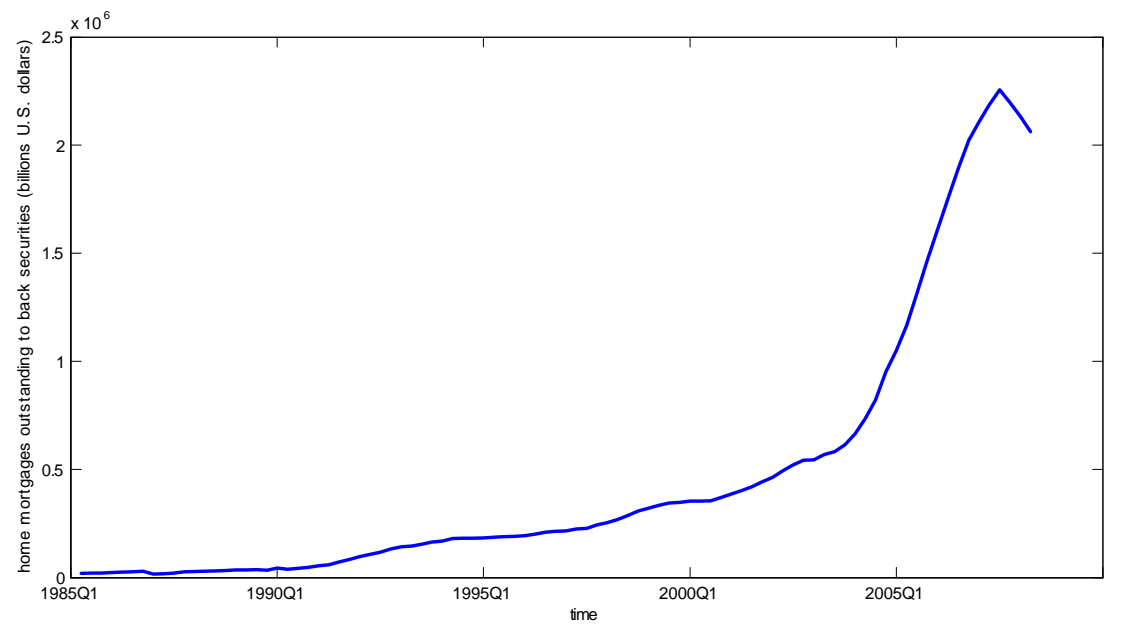

Figure 3: Amount of home mortgages outstanding used to back securities in the U.S. in billions of dollar for the time period from 1985Q1 to 2008Q1. 


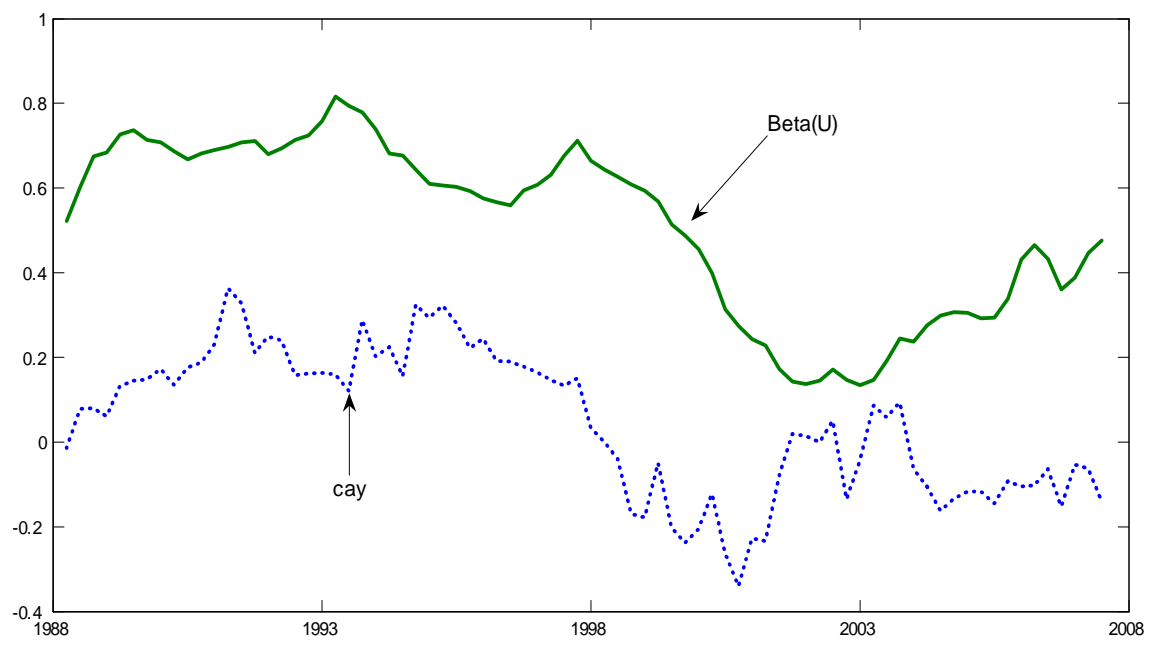

Figure 4: U.S. cay (multiplied by 10) vs. 12-quarter moving average of risk sharing coefficients obtained from a sequence of cross-sectional risk sharing regressions $\Delta \widetilde{c}_{t}^{k}=\beta(t) \Delta \widetilde{g d p_{t}^{k}}+\tau_{t}+\varepsilon_{t}^{k}$. 